\title{
SOLO UN OBJETO
}

Javier Martínez Villarroya*

Al arqueólogo, que desenterrando objetos disimula que siembra sueños.

Te ganarás el pan con el sudor de tu frente, hasta que vuelvas a la misma tierra de la cual fuiste formado, pues polvo eres y en polvo te convertirás.

Génesis 3,19

Mi historia es tan larga que no me cabe en el recuerdo. Algo así le debe de pasar al cosmos. El cielo de perpetua noche me mira bajo las antorchas inmortales.

Todo es frío y noche, noche y frío. Se suceden horas, días y lustros, décadas, siglos y milenios... y no sucede nada. Solo frío y noche, noche y frío. Entre hielos huérfanos de agua y oasis desérticos de aire permanezco petrificada en lo más hondo de la Tierra. Espero la salida del príncipe prometido, que no nace, $\mathrm{y}$ espera, $\mathrm{y}$ no quiere, $\mathrm{y}$ me acurruco en la panza de la madriguera. Busco el calor del hogar entre la magmática amalgama de gamas y omegas de la magnética madre planetaria. En el útero del mundo hace calor, pero no en sus lindes; como todas las madres la Tierra aprieta y empuja con delicadeza rocosa, severa, marmórea. Ha parido, no hay espacio, dice, y me destierra a mí para incubarlos a ellos. Me alejo del cóncavo regazo del universo... Los que ululan forjan mi primera identidad: la eterna noche y sus pálidos vientos me hielan los huesos que no tengo y, rigurosos, me convierten en piedra. Lo que en mí fue fuego es ahora piedra. Lo que en mí fue magma es ahora piedra. Lo que en mí fue lava es ahora piedra.

* Doctor en filosofía por la Universitat de Barcelona. Profesor del Departamento Académico de Lenguas, ITAM. 
Pasan estrellas infinitas infinitas veces por el techo del mundo, y yo permanezco quieta, acurrucada, fría... Vitrales rocosos, pétrea filigrana, piedra incansable, eso soy hasta que gigantes atléticos aúpan al primer sol, y el primer sol aúpa la historia entera. Curetes, bacabes, atlas y prometeos, Este, Oeste, Norte y Sur... todos se alzan inexpugnables en rincones definitivos. Sin criptonitas que puedan arrodillarlos, por los siglos de los siglos aguantan el paso del cielo y el peso del tiempo.

El niño sol deshace mis adentros; por afuera me difuminan vientos celosos y mongólicos. La vagina del cielo — ¡horizonte ruborizado!cicatriza entre nubes aurorales. Rojo su retoño me derrite... Resquebrajada mi alma y con el cuerpo borrado, amanezco arena. Lo que en mí fue piedra es ahora tierra. Lo que en mí fue hueso es ahora tierra. Lo que en mí fue frío es ahora tierra.

Los granos se acercan y se alejan caleidoscópicos, y agrupan constelaciones de huesos dispersados. Cuando era arena era hora e ira (hora de reloj bulboso y grávido, e ira de mordisco polvoso de teatro). A la vera del gran río, manos negras de mujer morena me rescatan, y el perfil me acarician en el fluvial lecho. Con cosquillas, paciencia y ojos me arrulla la madre, madriz y madrina. Hiriéndose la piel con cicatrices, halla la mía, inorgánica y porosa: me ha dado forma, me ha dado límite, me ha dado alma. ¿Acaso engendrar no es cicatrizar? Ve mi contorno y me pare del lodo. Lo que en mí fue grano es ahora copa. Lo que en mí fue lodo es ahora copa. Lo que en mí fue fango es ahora copa.

En la lengua de aquel pueblo es mi nombre bek. Significa corazón y caldero, ofrenda y gracias. Para las gentes morenas todo corazón es el gran caldero, y todo caldero un pequeño corazón. No es de extrañar que en mí todo quepa: los vinos que engendran fornicios y hombres, los aceites que bendicen los matrimonios de los hombres, las cenizas con que despiden a los últimos hombres... ¡Sirvo a ninfas y a emperadores, a ladrones y a jueces, a beatos y bufones! Yo soy el jeroglífico de la ausencia presente: me colmaron ayer los negros con las mieles de la vida, pero hoy iluminados me hartan con la certidumbre de la muerte. Presido bautizos y bautizos, bodas y bodas, bailes y bailes, pero apenas una única muerte. Encierro a los muertos y con muertos me encierran muerto 
bajo tierra. Tumba de lloradas cenizas... Cuna de simientes prometidas... Regreso al útero de la tierra. Dejo de ser ánfora y devengo tumba. Lo que en mí era vino es ahora sangre seca. Lo que en mí era aceite es ahora ceniza. Y regreso pétreo a las oscuras madrigueras solitarias de la tierra.

Hay sabios que eternizan el pasado. Y hay sabios que aniquilan el futuro. Entre ambos están las manos del que me rescata del cielo del suelo. Me busca a pinceladas entre un mar de arena, tierra y grava, y yo lo espero acurrucada en terracota entre sonrientes calaveras. Huelo el viento de la vida, el soplo del sol, el oxígeno de la aurora, pero de tanto aire, de tanto aire, me falta el aire y me desintegro. Mi muerte, encerrada bajo tierra, se esfuma ante la respiración del mundo desenterrado. 
CITAM Derechos Reservados.

La reproducción total o parcial de este artículo se podrá hacer si el ITAM otorga la autorización previamente por escrito. 